\title{
Pengaruh Penerapan E-Filling, Sosialisasi Perpajakan, Kinerja Account Representative, dan Sanksi Pajak terhadap Tingkat Kepatuhan WPOP
}

\author{
Lyana Oka Kusumayanthi ${ }^{1}$ \\ Herkulanus Bambang Suprasto ${ }^{2}$ \\ ${ }^{1,2}$ Fakultas Ekonomi dan Bisnis Universitas Udayana (Unud), Bali, Indonesia \\ e-mail: lyanaoka9@gmail.com
}

\begin{abstract}
ABSTRAK
Penelitian ini bertujuan untuk meneliti pengaruh penerapan $e$-filling, sosialisasi perpajakan, kinerja account representative dan sanksi pajak terhadap tingkat kepatuhan wajib pajak orang pribadi di KPP Pratama Gianyar. Penelitian ini dilakukan di KPP Pratama Gianyar. Jumlah sampel yang diambil sebanyak 100 wajib pajak orang pribadi, dengan metode purposive sampling. Pengumpulan data dilakukan melalui survei dan kuesioner. Teknik analisis yang digunakan adalah regresi linear berganda. Berdasarkan hasil penelitian yaitu penerapan e-filling, kinerja account representative dan sanksi pajak berpengaruh positif pada kepatuhan WPOP di KPP Pratama Gianyar, sedangkan sosialisasi perpajakan tidak berpengaruh pada WPOP di KPP Pratama Gianyar

Kata kunci: E-filling, sosialisasi perpajakan, kinerja account representative, sanksi pajak, dan kepatuhan wajib pajak orang pribadi.
\end{abstract}

\begin{abstract}
This study aims to examine the effect of the application of e-filling, tax socialization, account representative performance and taxation penalty on individual taxpayer compliance at KPP Pratama Gianyar. This research was conducted at KPP Pratama Gianyar. The samples used were 100 respondents to the method of determining the sample was purposive sampling. The data collection techniques questionnaire. data analysis technique used is multiple linear regression analysis. Based on the results of the study showed that the application of e-filling, account representative performance and taxation penalty had a positive effect on WPOP compliance at KPP Pratama Gianyar, while tax socialization did not affect the WPOP at KPP Pratama Gianyar.

Keywords: E-filing, tax socialization, account representative performance, taxation penalty, and individual taxpayer compliance.
\end{abstract}

\section{PENDAHULUAN}

Kepatuhan wajib pajak dapat didefinisikan sebagai sutau keadaan di mana Wajib Pajak memenuhi semua kewajiban perpajakan dan melaksanakan hak perpajakannya (Erawati, 2018). Seorang wajib pajak dikatakan patuh apabila sudah melaporkan kewajiban pajaknya dengan akurat dan tepat waktu (Mahangila, 2017). Wajib pajak dikatakan patuh apabila wajib pajak patuh dalam 
memenuhi dan melaksanakan kewajiban perpajakan sesuai dengan ketentuan dan hukum pajak yang berlaku (Tambun dan Kopong, 2017). Penerimaan pendapatan yang berasal dari sektor pajak dapat tercapai dengan maksimal apabila didukung dengan tingkat kepatuhan dalam memenuhi kewajiban perpajakan yang tinggi dari wajib pajak.

Kepatuhan wajib pajak merupakan hal sangat penting dalam sistem perpajakan di Indonesia (Sahyaanggara, 2016), namun hal tersebut tidak mudah untuk direalisasikan oleh setiap wajib pajak, hal ini juga terlihat dari tingkat kepatuhan WPOP di KPP Pratama Gianyar yang mengalami fluktuasi pada periode 2014 sampai 2017. Tingkat kepatuhan pelaporan SPT tahunan Wajib Pajak Orang Pribadi di KPP Pratama Gianyar tahun 2014-2017 disajikan pada Tabel 1 berikut.

Tabel 1.

Tingkat Kepatuhan WPOP di KPP Pratama Gianyar 2014-2017

\begin{tabular}{cccccc}
\hline No & Tahun & $\begin{array}{c}\text { WPOP } \\
\text { Terdaftar }\end{array}$ & $\begin{array}{c}\text { WPOP } \\
\text { Efektif }\end{array}$ & $\begin{array}{c}\text { WPOP yang } \\
\text { Menyampaikan SPT }\end{array}$ & \% Kepatuhan \\
\hline 1 & 2014 & 108.183 & 83.544 & 56.859 & $68,06 \%$ \\
2 & 2015 & 119.780 & 95.048 & 66.221 & $69,67 \%$ \\
3 & 2016 & 130.464 & 105.670 & 61.373 & $58,08 \%$ \\
4 & 2017 & 140.245 & 115.430 & 60.534 & $52,44 \%$ \\
\multicolumn{5}{l}{}
\end{tabular}

Tabel 1 menjelaskan bahwa persentase kepatuhan WPOP di KPP Pratama Gianyar mengalami fluktuasi selama tahun 2014 sampai 2017 meskipun terjadi jumlah WPOP yang terdaftar menigkat. Dapat dilihat bahwa persentase kepatuhan WPOP pada tahun 2014 sebesar 68,06 persen mengalami peningkatan yaitu 69,67 persen pada tahun 2015. Namun, tingkat kepatuhan WPOP mengalami penurunan yaitu 58,08 persen di tahun 2016 dan 52,44 persen di tahun 2017. Menurunnya tingkat kepatuhan WPOP dalam melaporkan SPT tahunan di tahun 2016 dan 2017 
yang menjadi alasan peneliti untuk melakukan penelitian kembali terkait dengan faktor-faktor yang mempengaruhi kepatuhan WPOP pada KPP Pratama Gianyar.

Menurut Undang-Undang Nomor 28 Tahun 2007 menjelaskan SKPKB adalah surat ketetapan pajak yang menentukan besarnya jumlah pokok pajak, jumlah kredit pajak, jumlah pembayaran pokok pajak, besarnya sanksi administrasi, dan jumlah yang masih harus dibayar. Jumlah penerbitan SKPKB untuk WPOP dari tahun 2014 sampai 2017 di KPP Pratama Gianyar disajikan pada Tabel 2 berikut.

Tabel 2.

Jumlah Penerbitan SKPKB untuk WPOP di KPP Pratama Gianyar

\begin{tabular}{cc}
\hline Tahun & SKPKB \\
\hline 2014 & 49 \\
2015 & 98 \\
2016 & 52 \\
2017 & 10 \\
\hline
\end{tabular}

Sumber: KPP Pratama Gianyar, 2018

Tabel 2 dapat dilihat bahwa masih adanya SKPKB yang diterbitkan pada tahun 2014 hingga 2017 oleh KPP Pratama Gianyar. Peningkatan jumlah SKPKB yang diterbitkan pada tahun 2014 sampai 2015 menunjukkan bahwa masih kurangnya kesadaran dari WPOP dalam melaksanakan kewajiban perpajakan, namun pada tahun 2016 dan 2017 terjadi penurunan jumlah SKPKB yang menunjukkan bahwa upaya Direktorat Jenderal Pajak untuk meningkatkan jumlah penerimaan pajak melalui fungsi penagihan kepada wajib pajak berjalan dengan baik sehingga di tahun 2016 dan 2017 terjadi pengurangan jumlah penerbitan SKPKB dan dapat meningkatkan kesadaran wajib pajak untuk patuh dalam menjalankan kewajiban perpajakannya.

Sistem self assessment telah diterima secara luas dalam pemungutan 
Lyana Oka Kusumayanthi dan Herkulaus Bambang Suprasto. Pengaruh ...

pajak di dunia (Gambo et al., 2014). Sistem ini diharapkan dapat meningkatkan pemahaman Wajib Pajak atas peraturan perpajakan. E-filling merupakan suatu sistem yang dapat memberikan manfaat sosial dan ekonomi yang signifikan (Shikar dan Gupta, 2017). E-Filling adalah sistem untuk mengirimkan dokumen pajak kepada departemen pajak penghasilan melalui internet atau koneksi langsung, biasanya tanpa perlu untuk menyerahkan dokumen dalam bentuk kertas (Barodiya dan Bhargava, 2015). Modernisasi perpajakan melalui e-filling merupakan suatu inovasi yang mengacu pada pengembangan teknologi infromasi yang tersedia untuk melaporkan dan mengirim SPT tahunan dapat dilakukan dengan mudah dan efisien karena adanya formulir elektronik yang teredia dalam sistem layanan pajak yang siap untuk digunakan oleh para pengguna layanan SPT sehingga pelaporan SPT dapat dilakukan kapan saja yang diinginkan oleh wajib pajak (Parwati et al., 2017). Hasil tersebut sejalan dengan penelitian Hartanti dan Husein (2017) bahwa penerapan sistem $e$-filling berpengaruh secara signifikan. Namun, hasil yang berbeda ditemukan oleh penelitian Sesa (2015) menunjukkan bahwa $e$-filling tidak berpengaruh terhadap kepatuhan wajib pajak.

Pendidikan pajak dan kesadaran wajib pajak memiliki peran penting untuk menjamin administrasi berjalan dengan baik (Redae dan Sekhon, 2016). Pengetahuan dan pemahaman yang lebih baik tentang undang-undang dan aturan pajak yang memungkinkan untuk memenuhi kewajiban wajib pajaknya (Xin et al., 2015). Sosialisasi perpajakan adalah upaya yang dilakukan oleh Direktorat Jenderal Pajak untuk memberikan sebuah pengertian, informasi dan bimbingan untuk semua pembayar pajak, untuk mencapai tujuan kegiatan sosialisasi pajak 
dibagi menjadi tiga yaitu kegiatan sosialisasi calon wajib pajak, kegiatan sosialisasi untuk pembayar pajak baru, dan kegiatan sosialisasi untuk wajib pajak terdaftar (Andreas dan Savitri, 2015). Pentingnya diadakan sosialisasi terkait penerapan sistem pajak online dalam pembayaran maupun pelaporan pajak yang berlaku saat ini merupakan salah satu cara yang perlu dilakukan oleh Ditjen Pajak untuk memberikan informasi dan pembinaan kepada wajib pajak tentang segala yang berhubungann dengan perpajakan (Rusmayani dan Supadmi, 2017). Hasil tersebut sejalan dengan penelitian Kamaruddin dan Suprapti (2017) bahwa sosialisasi perpajakan berpengaruh secara signifikan. Namun, hasil yang berbeda ditemukan oleh penelitian Yuliasari (2015) menunjukkan bahwa sosialisasi perpajakan tidak berpengaruh terhadap kepatuhan wajib pajak.

Account Representative adalah aparat pajak yang bertanggung jawab dalam pelaksanaan pelayanan dan pengawasan secara langsung untuk wajib pajak tertentu yang telah ditugaskan kepadanya, untuk meningkatkan kepatuhan wajib pajak maka pelayanan yang diberikan oleh kantor pelayanan pajak setempat menjadi pertimbangan yang cukup penting. Account Representative ini memiliki fungsi yang secara langsung berhubungan dengan Wajib pajak yaitu mencakup Edukasi, Konsultasi, dan Pengawasan (Widomoko dan Novryanti, 2017). Hasil tersebut sejalan dengan penelitian Farikha (2016) bahwa kinerja Account Representative berpengaruh secara signifikan. Namun, hasil yang berbeda ditemukan oleh penelitian Kristianti (2018) didapatkan hasil bahwa peran Account Representative tidak berpengaruh terhadap kepatuhan wajib pajak.

Kepatuhan wajib pajak juga dipengaruhi oleh sanksi perpajakan. Sanksi 
pajak sebagai pencegah yang efektif untuk mengendalikan perilaku dari wajib pajak (Devos, 2014). Menurut Handayani dan Laily (2017) meskipun adanya sanksi, masih banyak wajib pajak yang tidak patuh dalam membayar kewajiban perpajakannya. Pentingnya peninjauan kembali terkait dengan pembuatan sanksi perpajakan agar tidak terjadi penghindaran pajak oleh wajib pajak (Swistak, 2015). Hasil tersebut sejalan dengan penelitian Mutia (2014) bahwa sanksi pajak berpengaruh secara signifikan. Namun, hasil yang berbeda ditemukan oleh penelitian Abdi (2017) didapatkan hasil bahwa peran sanksi pajak tidak berpengaruh terhadap kepatuhan wajib pajak.

Berdasarkan fenomena rendahnya kepatuhan wajib pajak dan hasil riset terdahulu inkonsistensi pengaruh dari variabel-variabel independen yang mempengaruhi kepatuhan wajib pajak, maka penulis tertarik membuat penelitian dengan judul Pengaruh Penerapan E-Filling, Sosialisasi Perpajakan, Kinerja Account Representative dan Sanksi Pajak terhadap Tingkat Kepatuhan Wajib Pajak Orang Pribadi yang terdaftar di KPP Pratama Gianyar.

Berdasarkan teori atribusi menjelaskan terkait penyebab perilaku seseorang yang akan ditentukan apakah dari faktor internal atau dari faktor eksternal. Perilaku yang disebabkan oleh faktor internal adalah perilaku yang berada dalam kendali perilaku pribadi dari individu, sedangkan perilaku yang disebabkan oleh faktor eksternal adalah situasi atau keadaan tertentu yang akan memberikan pengaruh terhadap perilaku individu. Penggunaan teknologi komputer merupakan faktor eksternal yang dapat mempengaruhi perilaku atau 
persepsi wajib pajak yang berkaitan dengan kepatuhan terhadap kewajiban perpajakannya.

Berdasarkan teori TAM (Technology Acceptance Model) adalah suatu model yang dapat digunkaan untuk menganalisis dan memahami faktor-faktor yang dapat mempengaruhi diterimanya teknologi komputer. Persepsi kemudahan dan persepsi kegunaan yang menjadi penentu dari suatu sistem dapat diterima atau tidak. Penerapan $e$-filling merupakan bagian dari modernisasi sistem perpajakan yang dapat mempengaruhi tingkat kepatuhan wajib pajak, dengan e-filling dapat memudahkan wajib pajak dalam melaporkan SPT Tahunan secara online dan realtime melalui internet pada website Direktorat Jenderal Pajak.

Berdasarkan teori atribusi menjelaskan terkait penyebab perilaku seseorang yang akan ditentukan apakah dari faktor internal atau dari faktor eksternal. Penggunaan teknologi komputer merupakan faktor eksternal yang dapat mempengaruhi perilaku atau persepsi wajib pajak yang berkaitan dengan kepatuhan terhadap kewajiban perpajakannya. Berdasarkan teori Technology Acceptance Model (TAM) merupakan suatu model yang digunakan untuk menganalisis dan memahami faktor-faktor yang mempengaruhi diterimanya teknologi komputer. Penerapan e-filling merupakan bagian dari modernisasi sistem perpajakan yang dapat mempengaruhi tingkat kepatuhan wajib pajak, dengan $e$-filling dapat memudahkan wajib pajak dalam melaporkan SPT Tahunan secara online dan realtime melalui internet pada website Direktorat Jenderal Pajak. 
Penelitian yang dilakukan oleh Astuti (2015) serta Susmita dan Supadmi (2016) juga memperoleh hasil yang serupa bahwa e-filling berpengaruh positif terhadap kepatuhan wajib pajak. Hal ini dikarenakan dalam menggunakan sistem e-filling dapat memberikan manfaat dan kemudahan dalam melaksanakan kewajiban perpajakan. Penggunaan sistem e-filling dapat memberikan kenyamanan, kemudahan dan kepuasan bagi wajib pajak maka kepatuhan akan semakin meningkat, dengan adanya kemudahan dari penggunaan e-filling dan wajib pajak merasa puas dan nyaman, maka akan membuat WPOP semakin patuh dalam melaporkan pajaknya. Berdasarkan uraian tersebut maka hipotesis penelitian ini sebagai berikut:

$\mathrm{H}_{1}$ : Penerapan $e$-filling berpengaruh positif terhadap kepatuhan wajib pajak orang pribadi .

Berdasarkan teori atribusi menjelaskan terkait penyebab perilaku seseorang yang akan ditentukan apakah dari faktor internal atau dari faktor eksternal. Sosialisasi perpajakan merupakan faktor eksternal yang dapat memengaruhi tingkat kepatuhan wajib pajak, dengan diadakannya sosialisasi diharapkan mampu meningkatkan pemahaman dan kesadaran akan pentingnya peran pajak bagi negara sehingga wajib pajak akan mematuhi aturan yang berlaku dan akan melaksanakan kewajiban perpajakannya. Meningkatnya tingkat pengetahuan pajak dapat mempengaruhi tingkat kepatuhan wajib pajak (Manual \& Xin, 2016). Sosialisasi yang diberikan kepada wajib pajak diharapkan dapat memotivasi dan memberikan pemahaman terkait perpajakan dan aturannya sehingga dapat meningkatkan kepatuhan wajib pajak (Savitri dan Musfialdy, 2016). 
Berdasarkan penelitian dari Dharma dan Suardana (2017) yang menjelaskan bahwa sosialisasi perpajakan berpengaruh terhadap kepatuhan wajib pajak, hal ini dikarenakan sosialisasi perpajakan dapat memberikan pengetahuan serta pemahaman terkait sanksi dan sisem perpajakan kepada wajib pajak dan dapat menjadi motivasi bagi masyarakat untuk patuh dan mau membayar pajak sehingga akan dapat meningkatkan kepatuhan wajib pajak (Gustiari dan Suprasto, 2018). Wajib pajak dapat memperoleh informasi perpajakan melalui sosialisasi baik secara langsung maupun tidak langsung sehingga membuat wajib pajak menjadi paham mengenai aturan dan sistem perpajakan.

Sosialisasi perpajakan juga diharapkan berdampak pada meningkatnya jumlah wajib pajak dan tingkat kesadaran dari wajib pajak untuk patuh dalam membayar dan melaporkan SPT tahunan yang pada akhirnya akan dapat meningkatkan penerimaan negara dari sektor pajak. Berdasarkan uraian tersebut maka hipotesis penelitian ini sebagai berikut:

$\mathrm{H}_{2}$ : Sosialisasi perpajakan berpengaruh positif terhadap kepatuhan wajib pajak orang pribadi.

Berdasarkan teori atribusi menjelaskan terkait penyebab perilaku seseorang yang akan ditentukan apakah dari faktor internal atau dari faktor eksternal. Kinerja dari Account Representative merupakan faktor eksternal yang dapat memengaruhi tingkat kepatuhan wajib pajak, semakin baik pelayanan yang diberikan oleh Account Representative dalam membantu wajib pajak untuk dapat melaksanakan kewajiban perpajakannya maka akan dapat meningkatkan kepatuhan wajib pajak dalam melaporkan SPT tahunannya. 
Lyana Oka Kusumayanthi dan Herkulaus Bambang Suprasto. Pengaruh ...

Berdasarkan penelitian dari Setiawan dan Suyanto (2017), serta Farikha (2016) yang mendapatkan hasil bahwa kinerja Account Representative berpengaruh positif dan signifikan terhadap kepatuhan wajib pajak. Jika AR mampu melaksanakan tugasnya dengan baik maka AR dianggap memiliki kinerja yang baik pula sehingga wajib pajak juga akan beranggapan yang baik terkait dengan pelaksanaan tugasnya dengan memberikan bimbingan/himbauan, konsultasi, analisis dan pengawasan yang akan dapat membantu wajib pajak dalam menyelesaikan masalah perpajakannya. Sehingga akan membuat wajib pajak dengan sukarela melaksanakan kewajiban perpajakannya. Berdasarkan uraian tersebut maka hipotesis penelitian ini sebagai berikut:

$\mathrm{H}_{3}$ : Kinerja Account Representative berpengaruh positif terhadap kepatuhan wajib pajak orang pribadi.

Berdasarkan teori atribusi menjelaskan terkait penyebab perilaku seseorang yang akan ditentukan apakah dari faktor internal atau dari faktor eksternal. Sanksi pajak merupakan faktor eksternal yang dapat memaksa wajib pajak untuk patuh dan taat dengan aturan atau undang-undang yang berlaku dengan kata lain sanksi perpajakan merupakan alat pencegah yang efektif agar WPOP tidak melanggar norma perpajakan. Sanksi perpajakan dikenakan kepada para wajib pajak yang tidak mematuhi aturan dalam Undang-Undang Perpajakan, agar peraturan perpajakan dipatuhi maka harus ada sanksi perpajakan bagi para pelanggarnya (Siamena et al., 2017).

Pranata dan Setiawan (2015), serta Purnaditya dan Rohman (2015) yang menjelaskan bahwa sanksi pajak berpengaruh positif pada kepatuhan wajib pajak, hal tersebut dikarenakan semakin tinggi tingkat pemahaman wajib pajak mengenai 
sanksi perpajakan maka tingkat kepatuhan pajak akan semakin meningkat. Persepsi WPOP mengenai sanksi perpajakan akan dapat mempengaruhi kepatuhan WPOP dalam melaporkan pajaknya, apabila WPOP memiliki persepsi bahwa sanksi pajak memberikan kerugian bagi wajib pajak maka akan membuat WPOP melaporkan pajak dengan tepat waktu agar terhindar dari sanksi tersebut. Berdasarkan uraian tersebut maka hipotesis penelitian ini sebagai berikut:

$\mathrm{H}_{4}$ : Sanksi perpajakan berpengaruh positif terhadap kapatuhan wajib pajak orang pribadi

\section{METODE PENELITIAN}

Penelitian ini menggunakan pendekatan kuantitatif. Pendekatan kuantitatif merupakan pendekatan untuk meneliti populasi atau sampel tertentu yang bertujuan untuk menguji hipotesis yang telah ditetapkan (Sugiyono, 2017:13). Penelitian ini dilakukan di KPP Pratama Gianyar, KPP Pratama Gianyar memiliki cakupan wilayah kerja meliputi empat kabupaten yaitu Kabupaten Gianyar, Kabupaten Klungkung, Kabupaten Karangasem, dan Kabupaten Bangli. Objek dalam penelitian ini adalah kepatuhan Wajib Pajak Orang Pribadi yang terdaftar di KPP Pratama Gianyar, khususnya mengenai penerapan e-filling, sosialisasi perpajakan, kinerja Account Representative, dan sanksi pajak. Variabel dependen dalam penelitian ini adalah tingkat Kepatuhan WPOP (Y) dan variabel independen pada penelitian ini adalah penerapan e-filling $\left(\mathrm{X}_{1}\right)$, Sosialisasi Perpajakan $\left(\mathrm{X}_{2}\right)$, kinerja Account Representative $\left(\mathrm{X}_{3}\right)$, dan sanksi pajak $\left(\mathrm{X}_{4}\right)$. 
Lyana Oka Kusumayanthi dan Herkulaus Bambang Suprasto. Pengaruh ...

Pengukuran untuk variabel dependen dan independen yaitu dengan menggunakan kuesioner skala likert dengan skala 4. Penelitian ini menggunakan data primer dalam pengumpulan datanya, sehingga data yang diperoleh secara langsung dari sumber penelitian. WPOP yang efektif di KPP Pratama Gianyar merupakan responden pada penelitian ini. Data yang diperoleh dari responden yang telah mengisi kuesioner yang terdiri dari beberapa pernyataan yang sesuai dengan indikator untuk meneliti masing-masing variabel.

Dalam penelitian ini yang menjadi populasi adalah wajib pajak orang pribadi yang terdaftar di KPP Pratama Gianyar per 31 Desember 2017. Mencakup seluruh wilayah kerja KPP Pratama Gianyar yaitu Kabupaten Gianyar, Kabupaten Klungkung, Kabupaten Karangasem, dan Kabupaten Bangli yaitu sejumlah 140.245 Wajib Pajak Orang Pribadi. Metode penentuan sampel dalam penelitian ini menggunakan teknik purposive sampling, yaitu teknik penentuan sampel dengan pertimbangan tertentu (Sugiyono, 2017:85). Adapun yang menjadi kriteria sampel dalam penelitian ini yaitu responden yang merupakan WPOP efektif yang mengisi SPT tahunan 1770 S dan 1770 yang terdaftar di KPP Pratama Gianyar per 31 Desember 2017 dan pernah menggunakan $e$-filling.

Sampel penelitian ini berjumlah 100 responden yaitu WPOP efektif yang terdaftar di KPP Pratama Gianyar. Jumlah serta ukuran sampel ditentukan dengan rumus Slovin, sebagai berikut:

$n=\frac{N}{1+N e^{2}}$ 
Keterangan:

$\mathrm{N}=$ Jumlah Populasi

$n=$ Ukuran Sampel

$\mathrm{e}^{2}=$ Nilai kritis (batas ketelitian 0,1$)$

Perhitungan sampel:

$n=\frac{140.245}{1+140.245(0,1)^{2}}$

$n=99,92$

$n=100$ (dibulatkan)

Teknik analisis data yang digunakan dalam penelitian ini yaitu analisis statistik deskriptif untuk mendeskripsikan data menjadi sebuah informasi yang mudah dipahami, uji instrument penelitian yang terdiri dari uji validitas dan uji reliabilitas, uji asumsi klasik yang mencangkup uji normalitas, multikolinearitas dan heteroskedastisitas. Analisis regresi berganda digunakan untuk mengetahui pengaruh variabel independen terhadap variabel dependen. Model analisis regresi linier berganda dirumuskan sebagai berikut.

$\mathrm{Y}=\beta_{0}-\beta_{1} X_{1}+\beta_{2} X_{2}+\beta_{3} X_{3}+\beta_{4} X_{4}+e$

Keterangan dari persamaan diatas adalah sebagai berikut:

$\begin{array}{ll}\mathrm{Y} & =\text { Kepatuhan Wajib Pajak } \\ \mathrm{X}_{1} & =\text { Penerapan E-Filling } \\ \mathrm{X}_{2} & =\text { Sosialisasi Perpajakan } \\ \mathrm{X}_{3} & =\text { Kinerja Account Representative } \\ \mathrm{X}_{4} & =\text { Sanksi Perpajakan } \\ \alpha & =\text { Konstanta } \\ \beta & =\text { Koefisien regresi } \\ \mathrm{e} & \end{array}$


Lyana Oka Kusumayanthi dan Herkulaus Bambang Suprasto. Pengaruh ...

\section{HASIL DAN PEMBAHASAN}

KPP Pratama Gianyar adalah salah satu Unit Organisasi di jajaran Direktorat Jenderal Pajak yang berada di bawah dan bertanggungjawab langsung kepada Kepala Kantor Wilayah DJP Bali yang berkedudukan di Denpasar. KPP Pratama Gianyar menaungi beberapa kabupaten, antara lain: Kabupaten Gianyar, Kabupaten Bangli, Kabupaten Karangasem, dan Kabupaten Klungkung. Data penelitian ini didapatkan dari hasil penyebaran kuesioner kepada 100 responden yang dipilih berdasarkan teknik purposive sampling dan telah memenuhi kriteria yaitu WPOP efektif yang mengisi SPT 1770 S dan 1770 yang terdaftar di KPP Pratama Gianyar dan pernah menggunakan e-filling. Ringkasan data untuk krakteristik responden disajikan pada Tabel 3.

Tabel 3.

Daftar Penyebaran Kuesioner

\begin{tabular}{|c|c|c|c|}
\hline Data Deskriptif & Klasifikasi & $\begin{array}{l}\text { Jumlah } \\
\text { (Orang) }\end{array}$ & $\begin{array}{c}\text { Persentase } \\
(\%)\end{array}$ \\
\hline Pekerjaan & $\begin{array}{l}\text { 1. PNS } \\
\text { 2. Pegawai Swasta } \\
\text { 3. Wiraswasta } \\
\text { Total }\end{array}$ & $\begin{array}{c}30 \\
27 \\
43 \\
100\end{array}$ & $\begin{array}{c}30 \\
27 \\
43 \\
100\end{array}$ \\
\hline $\begin{array}{c}\text { Formulis SPT } \\
\text { Tahunan }\end{array}$ & $\begin{array}{ll}\text { 1. } & 1770 \mathrm{~S} \\
\text { 2. } & 1770 \\
\text { Total }\end{array}$ & $\begin{array}{c}57 \\
43 \\
100\end{array}$ & $\begin{array}{c}57 \\
43 \\
100\end{array}$ \\
\hline Pendidikan Terakhir & $\begin{array}{l}\text { 1. SMA/SMK } \\
\text { 2. Diploma } \\
\text { 3. S1 } \\
\text { 4. S2 } \\
\text { Total }\end{array}$ & $\begin{array}{c}12 \\
15 \\
57 \\
16 \\
100\end{array}$ & $\begin{array}{c}12 \\
15 \\
57 \\
16 \\
100\end{array}$ \\
\hline Tempat Domisili & $\begin{array}{l}\text { 1. Klungkung } \\
\text { 2. Karangasem } \\
\text { 3. Gianyar } \\
\text { 4. Bangli } \\
\text { Total }\end{array}$ & $\begin{array}{c}16 \\
27 \\
43 \\
14 \\
100\end{array}$ & $\begin{array}{c}16 \\
27 \\
43 \\
14 \\
100\end{array}$ \\
\hline
\end{tabular}

Sumber: Data diolah, 2019 
Tabel 3 memberikan gambaran bahwa jumlah responden yang mengisi formulir SPT 1770 S sebanyak 57 persen dan formulir SPT 1770 sebanyak 43 persen. Berdasarkan jenis pekerjaannya, jumlah responden bekerja sebagai PNS berjumlah 30 persen, pegawai swasta berjumlah 27 persen dan wiraswasta sebanyak 43 persen. Jumlah responden dengan tingkat pendidikan terakhir Strata 1 (S1) sebanyak 57 persen, Diploma sebanyak 15 persen, Strata 2 (S2) sebanyak 16 persen dan SMA/SMK sebanyak 12 persen.

Statistik deskriptif merupakan uji yang dipergunakan untuk mendeskripsikan data dalam penelitian yang meliputi jumlah sampel yang diamati, nilai minimum, nilai maksimum, nilai rata-rata, dan standar deviasi.

Tabel 4.

Hasil Statistik Deskriptif

\begin{tabular}{lccccc}
\hline \multicolumn{1}{c}{ Variabel } & $\mathrm{N}$ & Minimum & Maksimum & Mean & Std. Deviasi \\
\hline Penerapan E-filling $\left(\mathrm{X}_{1}\right)$ & 100 & 23,00 & 44,00 & 37,82 & 4,15 \\
Sosialisasi Perpajakan $\left(\mathrm{X}_{2}\right)$ & 100 & 6,00 & 16,00 & 13,45 & 2,04 \\
Kinerja Account & 100 & 25,00 & 36,00 & 31,36 & 3,42 \\
Representative $\left(\mathrm{X}_{3}\right)$ & & & & & \\
Sanksi Perpajakan $\left(\mathrm{X}_{4}\right)$ & 100 & 11,00 & 16,00 & 14,02 & 1,65 \\
Kepatuhan WPOP $(\mathrm{Y})$ & 100 & 12,00 & 20,00 & 17,45 & 2,11 \\
Valid N (Listwis) & 100 & & & & \\
\hline Sumber: Data diolah, 2019 & & & & &
\end{tabular}

Berdasarkan statistik deskriptif yang nilai minimum dari besaran penerapan e-filling sebesar 23,00 dan nilai maksimum sebesar 44,00. Nilai rata-rata dari penerapan e-filling adalah 37,82. Nilai standar deviasi sebesar 4,15 yang berarti data penerapan e-filling cenderung bervariasi dengan sebaran data normal cenderung ke kanan. Nilai minimum dari sosialisasi perpajakan sebesar 6,00 dan nilai maksimum sebesar 16,00. Nilai rata-rata dari sosialisasi perpajakan adalah 
Lyana Oka Kusumayanthi dan Herkulaus Bambang Suprasto. Pengaruh ...

13,45. Nilai standar deviasi sebesar 2,04 yang berarti data sosialisasi perpajakan cenderung bervariasi dengan sebaran data normal cenderung ke kanan. Nilai minimum dari kinerja account representative sebesar 25,00 dan nilai maksimum sebesar 36,00. Nilai rata-rata dari kinerja account representative adalah 31,36. Nilai standar deviasi sebesar 3,42 yang berarti data kinerja account representative cenderung bervariasi dengan sebaran data normal. Nilai minimum dari sanksi perpajakan sebesar 11,00 dan nilai maksimum sebesar 16,00. Nilai rata-rata dari variabel sanksi perpajakan adalah 14,02. Nilai standar deviasi sebesar 1,65 yang berarti data sanksi perpajakan cenderung bervariasi dengan sebaran data normal cenderung ke kanan. Nilai minimum dari kepatuhan WPOP sebesar 12,00 dan nilai maksimum sebesar 20,00. Nilai rata-rata dari kinerja karyawan adalah 17,45. Nilai standar deviasi sebesar 2,11 yang berarti data kepatuhan WPOP cenderung bervariasi dengan sebaran data normal.

Pengujian validitas ini dilakukan dengan menghitung nilai Pearson Correlation. Jumlah item dalam kuesioner ini adalah sebanyak 33 item. Tabel 5 menyajikan hasil uji validitas instrument penelitian sebagai berikut. 
Tabel 5.

Hasil Uji Validitas

\begin{tabular}{|c|c|c|c|c|}
\hline No & Variabel & $\begin{array}{c}\text { Item } \\
\text { Pernyataan } \\
\end{array}$ & $\begin{array}{c}\text { Pearson } \\
\text { correlation }\end{array}$ & Keterangan \\
\hline \multirow[t]{11}{*}{1} & Penerapan E-Filling & $\mathrm{X} 1.1$ & 0,564 & Valid \\
\hline & & $\mathrm{X} 1.2$ & 0,740 & Valid \\
\hline & & $\mathrm{X} 1.3$ & 0,740 & Valid \\
\hline & & $\mathrm{X} 1.4$ & 0,638 & Valid \\
\hline & & $\mathrm{X} 1.5$ & 0,543 & Valid \\
\hline & & $\mathrm{X} 1.6$ & 0,449 & Valid \\
\hline & & $\mathrm{X} 1.7$ & 0,613 & Valid \\
\hline & & $\mathrm{X} 1.8$ & 0,640 & Valid \\
\hline & & $\mathrm{X} 1.9$ & 0,693 & Valid \\
\hline & & $\mathrm{X} 1.10$ & 0,598 & Valid \\
\hline & & $\mathrm{X} 1.11$ & 0,740 & Valid \\
\hline \multirow[t]{4}{*}{2} & Sosialisasi Perpajakan & $\mathrm{X} 2.1$ & 0,773 & Valid \\
\hline & & $\mathrm{X} 2.2$ & 0,804 & Valid \\
\hline & & $\mathrm{X} 2.3$ & 0,812 & Valid \\
\hline & & $\mathrm{X} 2.4$ & 0,777 & Valid \\
\hline \multirow[t]{9}{*}{3} & Kinerja Account Representative & X3.1 & 0,725 & Valid \\
\hline & & X3.2 & 0,795 & Valid \\
\hline & & X3.3 & 0,667 & Valid \\
\hline & & X3.4 & 0,740 & Valid \\
\hline & & $\mathrm{X} 3.5$ & 0,653 & Valid \\
\hline & & X3.6 & 0,594 & Valid \\
\hline & & X3.7 & 0,746 & Valid \\
\hline & & X3.8 & 0,718 & Valid \\
\hline & & X3.9 & 0,577 & Valid \\
\hline \multirow[t]{4}{*}{4} & Sanksi Perpajakan & $\mathrm{X} 4.1$ & 0,770 & Valid \\
\hline & & $\mathrm{X} 4.2$ & 0,832 & Valid \\
\hline & & $\mathrm{X} 4.3$ & 0,874 & Valid \\
\hline & & X4.4 & 0,735 & Valid \\
\hline \multirow[t]{5}{*}{5} & Kepatuhan WPOP & Y.1 & 0,836 & Valid \\
\hline & & Y.2 & 0,811 & Valid \\
\hline & & Y.3 & 0,750 & Valid \\
\hline & & Y.4 & 0,803 & Valid \\
\hline & & Y.5 & 0,562 & Valid \\
\hline
\end{tabular}

Sumber: Data diolah, 2019

Hasil dari uji validitas menyatakan bahwa instrumen - instrumen pada setiap variabel dalam penelitian ini adalah valid. Hal ini dikarenakan korelasi antara skor masing - masing pertanyaan dengan skor total besarnya diatas 0,30 . 
Tabel 6.

Hasil Uji Reliabilitas

\begin{tabular}{lcc}
\hline \multicolumn{1}{c}{ Variabel } & Koefisien Alpha Cronbach & Keterangan \\
\hline Penerapan E-Filling & 0,841 & Reliabel \\
Sosialisasi Perpajakan & 0,798 & Reliabel \\
Kinerja Account Representative & 0,863 & Reliabel \\
Sanksi Perpajakan & 0,817 & Reliabel \\
Kepatuhan WPOP & 0,810 & Reliabel \\
\hline
\end{tabular}

Sumber: Data diolah, 2019

Hasil uji reliabilitas menyatakan bahwa semua variabel reliable karena nilai Cronbach's Alpa yang lebih besar dari 0,70 sehingga layak untuk digunakan sebagai alat instrumen kuesioner dalam penelitian ini.

Tabel 7.

Hasil Uji Normalitas

Unstandardized Residual

$\mathrm{N}$

Normal Parameters ${ }^{\mathrm{a}, \mathrm{b}}$

Most Extreme Differences

Test Statistic

Asymp. Sig. (2-tailed)

Sumber: Data diolah, 2019

Hasil uji normalitas menunjukkan bahwa nilai Asymp. Sig sebesar 0,200 yang lebih besar dari 0,05. Hal ini menunjukkan bahwa data berdistribusi normal.

Tabel 8.

Hasil Uji Multikolinearitas

\begin{tabular}{clcc}
\hline No & \multicolumn{1}{c}{ Variabel } & Nilai Tolerance & Nilai VIF \\
\hline 1 & Penerapan E-filling $\left(\mathrm{X}_{1}\right)$ & 0,527 & 1,898 \\
2 & Sosialisasi perpajakan $\left(\mathrm{X}_{2}\right)$ & 0,944 & 1,060 \\
3 & Kinerja Account Representative $\left(\mathrm{X}_{3}\right)$ & 0,511 & 1,957 \\
4 & Sanksi Perpajakan $\left(\mathrm{X}_{4}\right)$ & 0,876 & 1,141 \\
\hline \multicolumn{2}{l}{ Sumber: Data diolah, 2019}
\end{tabular}

Sumber: Data diolah, 2019

Hasil Uji Multikolinearitas menunjukkan bahwa nilai tolerance lebih besar dari 0,10 dan nilai VIF diperoleh lebih kecil dari 10 untuk seluruh variabel bebas. 
Jadi dapat disimpulkan bahwa tidak adanya korelasi antara sesama variabel bebas dalam model regresi, hal ini berarti tidak terdeteksi masalah multikolinearitas.

Tabel 9.

Hasil Uji Heterokedastisitas

\begin{tabular}{clcc}
\hline No & \multicolumn{1}{c}{ Variabel } & P-value & Keterangan \\
\hline 1 & Penerapan $e$-filling $\left(\mathrm{X}_{1}\right)$ & 0,888 & Bebas Heteroskedastisitas \\
2 & Sosialisasi perpajakan $\left(\mathrm{X}_{2}\right)$ & 0,897 & Bebas Heteroskedastisitas \\
3 & Kinerja account representative $\left(\mathrm{X}_{3}\right)$ & 0,929 & Bebas Heteroskedastisitas \\
4 & Sanksi perpajakan $\left(\mathrm{X}_{4}\right)$ & 0,712 & Bebas Heteroskedastisitas \\
\hline
\end{tabular}

Sumber: Data diolah, 2019

Hasil uji Heterosekdastisitas menunjukkan bahwa nilai $P$-value $>0,05$ pada masing-masing variabel pada model regresi, hal tersebut berarti bahwa model regresi tersebut tidak terdapat gejala heteroskedastisitas.

Tabel 10.

Hasil Analisis Regresi Linear Berganda

\begin{tabular}{|c|c|c|c|c|c|}
\hline \multirow[t]{2}{*}{ Model } & \multicolumn{2}{|c|}{$\begin{array}{l}\text { Unstandardized } \\
\text { Coefficients }\end{array}$} & \multirow{2}{*}{$\begin{array}{c}\begin{array}{c}\text { Standardized } \\
\text { Coefficients }\end{array} \\
\text { Beta }\end{array}$} & \multirow[t]{2}{*}{$\mathrm{t}$} & \multirow[t]{2}{*}{$P$-value } \\
\hline & $\mathrm{B}$ & $\begin{array}{l}\text { Std. } \\
\text { Error }\end{array}$ & & & \\
\hline (Constant) & $-1,852$ & 1,441 & & $-1,285$ & 0,202 \\
\hline Penerapan $e$-filling $\left(\mathrm{X}_{1}\right)$ & 0,280 & 0,039 & 0,551 & 7,158 & 0,000 \\
\hline Sosialisasi perpajakan $\left(\mathrm{X}_{2}\right)$ & 0,054 & 0,059 & 0,053 & 0,917 & 0,362 \\
\hline $\begin{array}{l}\text { Kinerja Account Representative } \\
\left(\mathrm{X}_{3}\right)\end{array}$ & 0,170 & 0,048 & 0,276 & 3,538 & 0,001 \\
\hline Sanksi perpajakan $\left(\mathrm{X}_{4}\right)$ & 0,190 & 0,076 & 0,148 & 2,486 & 0,015 \\
\hline$R$ Square & & 0,704 & & & \\
\hline Adjusted R Square & & 0,691 & & & \\
\hline $\mathrm{F}$ & & 56,366 & & & \\
\hline$P$-value $\mathrm{F}$ & & 0,000 & & & \\
\hline
\end{tabular}

Sumber: Data diolah, 2019

Persamaan regresi dalam penelitian ini disajikan sebagai berikut.

$Y=-1,852+0,280 X_{1}+0,054 X_{2}+0,170 X_{3}+0,190 X_{4}+e$

Nilai konstanta sebesar $-1,852$ memiliki arti secara statistik apabila nilai penerapan e-filling $\left(\mathrm{X}_{1}\right)$, sosialisasi perpajakan $\left(\mathrm{X}_{2}\right)$, kinerja account representative $\left(\mathrm{X}_{3}\right)$, dan sanksi pajak $\left(\mathrm{X}_{4}\right)$ sama dengan nol (tetap atau tidak berubah), menyebabkan kepatuhan wajib pajak orang pribadi di KPP Pratama Gianyar (Y) dalam memenuhi kewajiban perpajakannya akan menurun sebesar 
Lyana Oka Kusumayanthi dan Herkulaus Bambang Suprasto. Pengaruh ...

konstantanya. Nilai koefisien regresi $\mathrm{X}_{1}$ sebesar 0,280 dan P-value sebesar 0,000 menunjukkan bahwa jika penerapan e-filling $\left(\mathrm{X}_{1}\right)$ bertambah 1 satuan maka nilai kepatuhan WPOP (Y) akan naik sebesar 0,280 satuan dengan asumsi variabel lainnya konstan dengan tingkat $P$-value sebesar 0,000 . Nilai koefisien regresi $\mathrm{X}_{2}$ sebesar 0,054 dan P-value sebesar 0,362 menunjukkan bahwa jika sosialisasi perpajakan $\left(\mathrm{X}_{2}\right)$ bertambah 1 satuan maka nilai kepatuhan WPOP (Y) akan naik sebesar 0,054 satuan dengan asumsi variabel lainnya konstan dengan tingkat $P$ value sebesar 0,362. Nilai koefisien regresi $\mathrm{X}_{3}$ sebesar 0,170 dan P-value sebesar 0,001 menunjukkan bahwa jika nilai kinerja account representative $\left(\mathrm{X}_{3}\right)$ bertambah 1 satuan maka nilai kepatuhan WPOP (Y) akan naik sebesar 0,170 satuan dengan asumsi variabel lainnya konstan dengan tingkat $P$-value sebesar 0,001. Nilai koefisien regresi $\mathrm{X}_{4}$ sebesar 0,190 dan $P$-value sebesar 0,015 menunjukkan bahwa jika nilai sanksi perpajakan $\left(\mathrm{X}_{4}\right)$ bertambah 1 satuan maka nilai kepatuhan WPOP (Y) akan naik sebesar 0,190 satuan dengan asumsi variabel lainnya konstan dengan tingkat $P$-value sebesar 0,015 .

Berdasarkan Tabel 10 menunjukkan nilai F hitung sebesar 56,366 dengan tingkat signifikansi $\mathrm{F}$ atau $\mathrm{P}$-value sebesar $0,000<\alpha=0,05$. Hal ini menunjukkan bahwa regresi ini layak digunakan sebagai alat analisis untuk menguji pengaruh variabel bebas pada variabel terikat. Berdasarkan hasil analisis nilai Adjusted $R$ Square sebesar 0,691. Hal tersebut menjelaskan bahwa perubahan yang terjadi pada kepatuhan WPOP dapat dijelaskan oleh variabel penerapan e-filling, sosialisasi perpajakan, kinerja account representative, dan sanksi perpajakan 
sebesar 69,1 persen, sedangkan 30,9 persen dapat dijelaskan oleh faktor lain yang tidak diuji dalam penelitian ini.

Hasil analisis menunjukkan nilai koefisien regresi variabel penerapan $e$ filling sebesar 0,280 dengan tingkat $P$-value sebesar $0,000<0,05$ maka $\mathrm{H}_{1}$ diterima. Hasil ini menunjukkan bahwa semakin baik sistem penerapan e-filling akan menyebabkan semakin tinggi tingkat kepatuhan WPOP. Hasil pengujian tersebut sesuai dengan hipotesis yang menyatakan bahwa penerapan e-filling berpengaruh positif pada kepatuhan WPOP di KPP Pratama Gianyar.

Hasil penelitian ini sesuai dengan teori Technology Acceptance Model, yaitu persepsi kemanfaatan dan kemudahan penggunaan dalam menggunaakan $e$ filling dapat meningkatkan kepatuhan WPOP. Hasil tersebut juga didukung oleh penelitian yang dilakukan oleh Susmita dan Supadmi (2016), serta Astuti (2015) yang menjelaskan bahwa penerapan $e$-filling dapat meningkatkan kepatuhan wajib pajak. Penerapan $e$-filling yang baik dapat membuat wajib pajak puas terhadap pelayanan yang diberikan maka akan dapat meningkatkan kepatuhan wajib pajak.

Hasil analisis menunjukkan nilai koefisien regresi variabel sosialisasi perpajakan sebesar 0,054 dengan tingkat $P$-value adalah 0,362 >0,05 maka $\mathrm{H}_{2}$ ditolak. Berdasarkan hasil uji tersebut tidak dapat membuktikan hipotesis kedua yang berarti bahwa sosialisasi perpajakan tidak berpengaruh pada kepatuhan wajib pajak orang pribadi di KPP Pratama Gianyar. Hal tersebut menunjukkan bahwa semakin tinggi atau baik sosialisasi perpajakan yang diberikan oleh KPP Pratama Gianyar maka tidak mempengaruhi kepatuhan wajib pajak orang pribadi di KPP Pratama Gianyar. 
Lyana Oka Kusumayanthi dan Herkulaus Bambang Suprasto. Pengaruh ...

Hasil tersebut juga didukung oleh penelitian yang dilakukan oleh Tawas et al., (2016), Yuliasari (2015), dan Lianty et al., (2017) yang menjelaskan bahwa sosialisasi perpajakan tidak berpengaruh terhadap kepatuhan wajib pajak orang pribadi. Hal ini dikarenkaan sosialisasi perpajakan yang baik belum tentu dapat mempengaruhi persepsi dari WPOP untuk patuh dalam menjalankan kewajiban perpajakannya, yang disebabkan karena wajib pajak tidak dapat memahami dengan baik materi atau informasi perpajakan yang disampaikan. Ketidakpahaman responden atau wajib pajak terhadap materi atau informasi perpajakan yang disampaikan dapat disebabkan karena jumlah wajib pajak yang mengikuti sosialisasi langsung tersebut cukup banyak dan kurangnya konsentrasi dalam mendengarkan sosialisasi sehingga materi atau informasi perpajakan yang disampaikan tidak dapat dipahami dengan baik secara menyeluruh kepada wajib pajak sehingga kegiatan sosialisasi tersebut tidak berjalan dengan efektif.

Hasil analisis menunjukkan nilai koefisien regresi variabel kinerja account representative 0,170 dengan tingkat $P$-value adalah $0,001>0,05$ maka $\mathrm{H}_{3}$ diterima. Hasil ini sesuai dengan hipotesis yang menyatakan bahwa kinerja account representative berpengaruh positif pada kepatuhan WPOP di KPP Pratama Gianyar. Hal tersebut dikarenakan account representative telah menjalankan tugas dan fungsinya secara optimal.

Kinerja account representative yang digambarkan dari kualitas pelayanan yang efektif karena sesuai dengan kebutuhan serta dapat memberikan manfaat bagi wajib pajak, selain itu memberikan solusi yang tepat serta berkomunikasi dengan baik dan memberikan konsultasi yang dapat membantu wajib pajak paham 
sehingga dapat meningkatkan kepatuhan wajib pajak orang pribadi dalam menjalankan kewajiban perpajakannya. Hasil penelitian ini didukung oleh penelitian yang dilakukan oleh Setiawan dan Suyanto (2017) serta Nuzula et al., (2015) yang menunjukkan bahwa semakin baik kinerja dari account representative maka akan meningkatkan kepatuhan WPOP dalam memenuhi kewajiban perpajakannya.

Hasil analisis menunjukkan nilai koefisien regresi variabel sanksi perpajakan sebesar 0,190 dengan tingkat $P$-value adalah 0,015 $<0,05$ maka $\mathrm{H}_{4}$ diterima. Hasil ini mendukung hipotesis yang menyatakan bahwa sanksi perpajakan berpengaruh positif pada kepatuhan WPOP di KPP Pratama Gianyar dikarenakan pengenaan sanksi pajak dapat membuat terpenuhinya kewajiban perpajakan oleh WPOP sehingga dapat meningkatkan kepatuhan, apabila sanksi pajak dapat memberikan kerugian jika tidak dipatuhi maka akan membuat wajib pajak melaporkan pajaknya tapt waktu untuk menghindari sanksi tersebut.

Hasil tersebut juga didukung oleh penelitian yang dilakukan oleh Pranata dan Setiawan (2015) serta Purnaditya dan Rohman (2015) yang mejelaskan bahwa sanksi perpajakan berpengaruh positif pada kepatuhan wajib pajak dalam penegakkan sanksi pajak, selain itu sanksi diperlukan agar tercipta kedisiplinan wajib pajak dalam melaksanakan kewajiban dalam hal pelaporan dan pembayaran pajak dengan tepat waktu. 
Lyana Oka Kusumayanthi dan Herkulaus Bambang Suprasto. Pengaruh ...

\section{SIMPULAN}

Berdasarkan hasil empat pengujian yang dilakukan, 3 pengujian mendukung hipotesis dan 1 pengujian tidak terbukti mendukung hipotesis yakni variabel penerapan $e$-filling, kinerja account representative, dan sanksi pajak berpengaruh positif pada kepatuhan WPOP di KPP Pratama Gianyar, sedangkan untuk variabel sosialisasi perpajakan tidak berpengaruh pada kepatuhan WPOP di KPP Pratama Gianyar. Hasil dari pengujian ini tidak dapat mendukung hipotesis yang menyatakan sosialisasi perpajakan berpengaruh terhadap kepatuhan WPOP di KPP Pratama Gianyar.

Saran yang dapat diberikan yaitu berdasarkan hasil penelitian menunjukkan bagi Direktorat Jenderal Pajak disarankan untuk meningkatkan penyempurnaan dan inovasi berkelanjutan mengenai sistem elektronik perpajakan yang ada sehingga akan lebih memudahkan dalam penggunaan $e$-filling bagi wajib pajak dalam melaporkan SPT Tahunannya. Bagi WPOP di KPP Pratama Gianyar diharapakan dapat mengikuti sosialisasi secara langsung yang diselenggarakan oleh KPP Pratama Gianyar agar dapat memperoleh informasi mengenai sistem dan aturan perpajakan dan dapat melakukan konsultasi kepada pihak petugas pajak apabila mempunyai permasalahan dan pertanyaan terkait dengan materi yang dijelaskan pada saat sosialisasi berlangsung. Bagi Pihak KPP Pratama Gianyar diharapkan dapat meningkatkan kegiatan sosialisasi secara langsung kepada masyarakat terkait dengan sistem perpajakan modern beserta sanksi perpajakan jika wajib pajak lalai dalam melaksanakan kewajiban dalam melaporkan dan membayar pajaknya. 


\section{REFERENSI}

Andreas, \& Savitri, E. (2015). The Effect of Tax Socialization, Tax Knowledge, Expediency of Tax ID Number and Service Quality on Taxpayers Compliance with Taxpayers Awareness as Mediating Variables. Procedia Social and Behavioral Sciences. https://doi.org/10.1016/j.sbspro.2015.11.024

Abdi, R. (2017). Pengaruh Sanksi Pajak, Kualitas Pelayanan dan Penerapan Sistem E-Filling Terhadap Kepatuhan Wajib Pajak Orang Pribadi (Studi Empiris Wajib Pajak Orang Pribadi Yang Terdaftar Di Kpp Pratama 1 Padang). Jurnal Akuntansi Universitas Negeri Padang.

Astuti, I.N. (2015). Analisis Penerapan E-Filing sebagai Upaya Meningkatkan Kepatuhan Wajib Pajak dalam Penyampaian Surat Pemberitahuan (SPT) Tahunan pada Kantor Pelayanan Pajak Pratama Gresik Utara. Jurnal Akuntansi Universitas Negeri Surabaya.

Barodiya, P., \& Bhargava, A. (2015). E-Filing Awareness of Income Tax returns, (June), 119-122.

Devos, K. (2014). Tax compliance theory and the literature. In Factors Influencing Individual Taxpayer Compliance Behaviour. https://doi.org/10.1007/978-94-007-7476-6

Dharma, G.P.E \& Suardana, K.L. (2014). Pengaruh Kesadaran Wajib Pajak, Sosialisasi Perpajakan, Kualitas Pelayanan pada Kepatuhan Wajib Pajak. EJurnal Akuntansi Universitas Udayana.

Erawati, T. \& Ratnasari, R. (2018). Pengaruh Penerapan E-Filling Terhadap Kepatuhan Wajib Pajak Dalam Menyampaikan Spt Tahunan Dengan Kepuasan Kualitas Pelayanan Sebagai Variabel Intervening (Studi Empiris Di Kabupaten Gunungkidul). Jurnal Akuntansi Universitas Sarjanawiyata Tamansiswa Yogyakarta.

Farikha, I. (2016). "Sosialisasi Peraturan Perpajakan dan Kinerja Account Representative kaitan dengan Kepatuhan Wajib Pajak". E-Journal STIESIA Surabaya

Gambo, E. J., Mas'ud, A., Nasidi, M., \& Oyewole, O. S. (2014). Tax Complexity and Tax Compliance in African Self-Assessment Environment. International Journal of Management Research \& Review, 4 (5), hal.575-582.

Gustiari, L. A., \& Suprasto, H. B. (2018). Sosialisasi Perpajakan Memoderasi Pengaruh Kewajiban Moral dan Kualitas Pelayanan pada Kepatuhan Wajib Pajak Kendaraan Bermotor Fakultas Ekonomi dan Bisnis Universitas Udayana ( Unud ), Bali , Indonesia Fakultas Ekonomi dan Bisnis Universitas 
Udayana ( Un, 24, 606-632.

Hartanti, E., \& Husein, S. (2018). Pengaruh Penerapan Sistem E-Filing, Pengetahuan Pajak, dan Sanksi Pajak Terhadap Kepatuhan Wajib Pajak Orang Pribadi. Jurnal Bisnis dan Komunikasi Sekolah Tinggi Ilmu Ekonomi Indonesia.

Handayani, U., \& Laily, N. (2017). The Influence of Consciousness, Tax Penalty, and the Quality of Tax Authorities Service on Tax Compliance. Journal of Accounting and Business Education, 1 (2), hal.286-297.

Kamaruddin, M. S., \& Suprapti, R. (2017). Analisis Pengaruh Sosialisasi Perpajakan Terhadap Tingkat Kepatuhan Wajib Pajak Di Kantor Pelayanan Pajak Pratama Sumbawa Besar Tahun 2011-2016. Jurnal Ekonomi dan Bisnis Universitas Samawa.

Kristianti, U. (2018). Pengaruh Kinerja Account Representative, Self Assessment System, Kualitas Pelayanan Pajak, dan Sanksi Perpajakan Terhadap Kepatuhan Wajib Pajak (Studi Empiris WP OP pada KPP Pratama Karanganyar). Jurnal Akuntansi Universitas Muhammadiyah.

Lianty, R.A. M., Hapsari, D.W., \& Kurnia. (2017). Pengetahuan Perpajakan, Sosialisasi Perpajakan, Dan Pelayanan Fiskus Terhadap Kepatuhan Wajib Pajak. Jurnal Riset Akuntansi Kontemporer (JRAK) Universitas Telkom, 9 (2): h: 55-65.

Lubis, R. K. (2018). Memperbaiki Kinerja Tax Ratio: Sebuah Pendekatan Makro. http://www.pajak.go.id/article/memperbaiki-kinerja-tax-ratio-sebuahpendekatan-makro. Diakses 24 Otober 2018.

Mahangila, D. N. (2017). The Impact Of Tax Compliance Costs On Tax, 3, 5781.

Manual, V., \& Xin, A. Z. (2016). Impact of Tax Knowledge, Tax Compliance Cost, Tax Deterrent Tax Measures towards Tax Compliance Behavior : A survey on Self-Employed Taxpayers in West Malaysia, 1(1), 56-70.

Mutia, S. P. T. (2014). Pengaruh sanksi perpajakan, kesadaran perpajakan, pelayanan fiskus, dan tingkat pemahaman terhadap kepatuhan wajib pajak orang pribadi.

Nuzula, F., Handayani, S. R., \& Azizah, D. F. (2015). Pengaruh Kualitas Pelayanan Dan Kinerja Account Representative Terhadap Kepatuhan Wajib Pajak (Studi Pada Kantor Pelayanan Pajak Pratama Pare Kab. Kediri). Jurnal Administrasi Bisnis-Perpajakan (JAB) Universitas Brawijaya. 
Pranata, P. A., \& Setiawan, P. E. (2015). Pengaruh Sanksi Perpajakan, Kualitas Pelayanan dan Kewajiban Moral pada Kepatuhan Wajib Pajak. E-Jurnal Akuntansi Universitas Udayana.

Purnaditya, R. R., \& Rohman, A. (2015). Pengaruh Pemahaman Pajak, Kualitas Pelayanan Dan Sanksi Pajak Terhadap Kepatuhan Pajak (Studi Empiris Pada WP OP yang Melakukan Kegiatan Usaha di KPP Pratama Semarang Candisari). E-journal Akuntansi Universitas Dipnonegoro.

Parwati, N. M. S., Tenripada, \& Zahra, F. (2017). The analysis of factors affecting the use of e-filing for individual taxpayers. Journal Accounting Universitas Islam Indonesia.

Redae, R. B., \& Sekhon, S. (2016). Taxpayers' knowledge and tax compliance behavior in Ethiopia: A study of Tigray State. International Journal of Management and Commerce Innovations, 3(2), 1090-1102.

Rusmayani, L., \& Supadmi, N. L. (2017). "Pengaruh Sosialisasi, Pengetahuan, Sanksi dan Kualitas Pelayanan pada Kepatuhan Wajib Pajak Kendaraan Bermotor". E-Jurnal Akuntansi Universitas Udayana.

Sahyaanggara. (2016). The Influence Of Taxpayers Compliance On The Effectiveness Revenue Of Income Tax In Majalengka Tax Service Office. International Journal of Accounting and Financial Management Research (IJAFMR).

Swistak, A. (2015). Tax Penalties in SME Tax Compliance. Financial Theory and Practice, 40 (1), hal.129-147.

Setiawan, A., \& Suyanto. (2017). Pengaruh Kinerja Account Representative, Self Assesment System, dan Pemeriksaan Pajak terhadap Tingkat Kepatuhan Wajib Pajak. Universitas Sarjanawiyata Tamansiswa Yogyakarta. Jurnal Bidang Ilmu Ekonomi. Vol. 12 No.1 2017. ISSN 2528-7672.

Savitri, E., \& Musfialdy. (2016). The Effect of Taxpayer Awareness, Tax Socialization, Tax Penalties, Compliance Cost at Taxpayer Compliance with Service Quality as Mediating Variable. Procedia - Social and Behavioral Sciences. https://doi.org/10.1016/j.sbspro.2016.05.051

Siamena, E., Sabijono, H., \& Warongan, J. D. . (2017). Pengaruh Sanksi Perpajakan dan Kesadaran Wajib Pajak terhadap Kepatuhan Wajib Pajak Orang Pribadi di Manado. Jurnal Riset Akuntansi Going Concern.

Sihar, T., \& Kopong, Y. (2017). 2017 The Effect Of E-Filing On The Of Compliance Individual Taxpayer, 13(1), 45-51. 
Kumar, S., \& Gupta, S. (2017). A Study On Income Tax Payers Perception Towards Electronic Filing, 22.

Sesa, E. S., Upa, V. A., \& Tjahjono, J. K. (2015). Pribadi Pada Penerapan e-Filing Terhadap Tahunan Di Kota Surabaya, 4(1), 70-78.

Susmita, N. L. S. \& P. R. (2016). Pengaruh Kualitas Pelayanan, Sanksi Perpajakan, Biaya Kepatuhan Pajak, dan Penerapan E-filing pada Kepatuhan Wajib pajak. Jurnal Akuntansi Universitas Udayana, 1239-1269.

Sugiyono. (2017). “Metodologi Penelitian Bisnis.” Bandung: Alfabeta.

Tawas, V. B. J., Poputra, A. T., \& Lambey, R. (2016). Pengaruh Sosialisasi Perpajakan, Tarif Pajak, dan Sanksi Perpajakan terhadap Kepatuhan Pelaporan Spt Tahunan Wajib Pajak Orang Pribadi (Studi Kasus Pada Kpp Pratama Bitung). E-Jurnal Akuntansi EMBA.

Undang-Undang Republik Indonesia Nomor 28 Tahun 2007 tentang Perubahan Ketiga Atas Undang-undang Nomor 6 Tahun 1983 tentang Ketentuan Umum dan Tata Cara Perpajakan. http://ketentuan.pajak.go.id/index.php?r=aturan/rinci\&idcrypt=oJamop0\%3D. Diakses pada tanggal 7 Desember 2018.

Xin, M. K. H., Khai, K. G., Fong, L. S., \& Chen, N. H. (2015). The International Journal Of Business \& Management Factors Affecting Individual Taxpayers ' Compliance in Malaysian Tax Filing System Abstract :, 3(9), 339-347.

Yuliasari, W. S. (2015). Pengaruh Sosialisasi Perpajakan, Pelayanan Fiskus, dan Sanksi Terhadap Kepatuhan Wajib Pajak Orang Pribadi (Studi pada Wajib Pajak Orang Pribadi di KPP Pratama Ponorogo). Jurnal Administrasi Bisnis Perpajakan (JAB); Vol. 4 No. 2. 